pressing the claims of the Society to a grant, it being over ten years since the Science and Art Department had conferred on it the sum of $£ 3,000$, long since expended in the erection of buildings and in improvements in the gardens. In last March the Aquarium House was formally reopened by Her Excellency, the Countess Cadogan. The committee, headed by Dr. Samuel Gordon and Lord Powerscourt, having for its object the erection of a memorial building to bear the name of the former Honorable Secretary of the Society, the late Dr. Samuel Haughton, has received much public sympathy and support.

\section{UNIVERSITY AND EDUCATIONAL NEWS.}

Mr. Joseph F. Loubat has given to Columbia University property valued at $\$ 1,000,000$, subject to a life annuity of $\$ 60,000$. This great sum is for the support of the library, and is to be named the 'Gaillerd-Loubat Library Endowment Fund.'

THE bill has been presented in the Maryland House of Delegates appropriating $\$ 100,000$ to the Johns Hopkins University. President Gilman has made a statement in which he explains how the income of the University has been decreased by the failure of the Baltimore \& Ohio Railroad ; in 1896-97 the income exclusive of the medical school and certain gifts given for special purposes was:

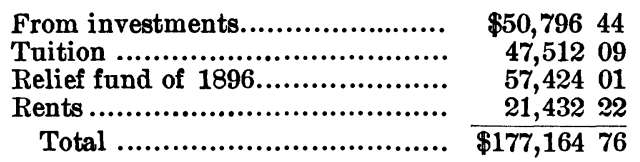

Expenses of the University were $\$ 191,156$. The buildings, land and equipment of the University are valued at slightly over a $\$ 1,000,000$.

THE Board of Trustees of Lafayette College have decided to rebuild Pardee Hall, the building containing the scientific departments, recently destroyed by fire, and to erect a chemical laboratory at a cost of $\$ 25,000$. Towards the cost of this building $\$ 10,000$ was subscribed at the meeting.

Dr. E. D. Pearsons, of Chicago, has donated $\$ 25,000$ to Pomona College, Pomona, Cal., which will be used by the trustees for the erection of a new science building.
The Jefferson Medical College, Philadelphia, has received, by the will of the late C. D. Shain, $\$ 7,000$ for scholarships and prizes.

THE annual report of the Board of Regents of the University of the State of New York states that the colleges and professional and technical schools of the State in seven years have increased their expenditures from $\$ 2,733,860$ to $\$ 5,771,325$; the value of buildings and grounds, from $\$ 15,129,028$ to $\$ 28,447,974$; the libraries and apparatus, from $\$ 1,896,959$ to $\$ 3,542,456$, and the total property owned, from $\$ 39,045,604$ to $\$ 77,148,944$.

The London University Commission Bill was introduced into the House of Lords by the Lord President of the Council on February 21st. It is identical with the bill of 1897 , except that the names of the commissioners are not included.

THE Austrian government has compromised with the rioting university students by suspending the lectures for the balance of the semester, but permitting them to count the time as spent in residence. At the commencement of the summer semester on March 21st all students will be required to renew their pledge to observe the academic regulations.

Professor Russell H. Chittenden, without resigning his professorship in Yale University, has accepted the directorship of the department of physiological chemistry in Columbia University. Dr. W. J. Gies has been appointed instructor and Messrs. A. H. Redland and H. E. McDermott have been appointed assistants in the department.

President A. S. Draper, of the University of Illinois, has been offered the superintendentship of schools of New York City.

Professor Luigi Lombardi has been appointed professor of technical physics at the Industrial Museum of Turin, in the room of the late Professor Galileo Ferraris.

\section{DISCUSSION AND CORRESPONDENCE.}

\section{MUSCULAR DISTURBANCES IN MONOCULAR VISION.}

IN a recent number of SCIENCE (February 25 1898) Mr. Charles H. Judd recounts some in- 
teresting experiments on 'Binocular Factors in Monocular Vision.' This title is somewhat misleading. The essential characteristic of binocular vision consists in the simultaneous formation of slightly dissimilar images on the two retinas, with corresponding modification of the perception of depth in space. Mr. Judd's experiments relate to variation in direction of the two visual lines, with resulting production of double images ; but fusion of these images is an indispensable requisite for the attainment of any binocular perception.

It is well known that most persons fail to perceive double images as phenomena attendant upon binocular vision. To perform binocular experiments the observer must have some training in the muscular control of the eyes, and also in visual perception. Such experiments occupied much of my attention some years ago (American Journal of Science, 1881-1883). In performing the first experiment described by Mr. Judd it is very easy to catch the heteronymous image, and by proper control of the eye to stop its motion instantly. The appearance of unrest of the object, to which he refers, is due to the motion of this image during the instant before fusion is attained. The visual line of the closed eye, as Mr. Judd correctly observes, does not converge toward that of the open eye. Since fusion of images is attained in natural binocular vision and without any conscious effort, on suddenly opening the unused eye, unconscious motion of both eyes results until fusion is secured. But the vision is strictly monocular until such fusion is completed, and the momentary illusion is not a binocular factor in such vision.

The experiment is perhaps most easily accomplished by covering one eye with the hand and suddenly removing this, instead of bringing the muscles of the eyelids into play. If the open eye be directed to some well illuminated object of known diameter and at a known distance, such as a clock dial, the angular displacement of the heteronymous image is easily found. It is only necessary to control the unused eye, resisting the tendency to secure fusion and noting the interval between corresponding edges of the two overlapping images. The ratio of this to the distance gives the angle.
The unused eye will in most cases be so directed that the two visual lines are approximately parallel. In cases of strabismus, external or internal, this parallelism is, of course, lost, but in such cases there is usually no power of binocular perception, one eye being habitually depended upon to the exclusion of the other.

When control of the eyes is lost temporarily through drowsiness the uncontrolled relation of the visual lines may be ascertained by winking one eye, if the observer is enough interested in binocular experiments to remember this, and to do this, in his semi-conscious condition. I have done so repeatedly, and have always found in my own case that the double images were homonymous; which indicates that the visual lines were crossed instead of divergent. I have watched the eyes of others under such conditions. In some cases the contraction of the rectus muscles was seen to be internal, in others external. No general rule on this subject can be formulated. It seems highly probable, however, that after consciousness becomes complete all the rectus muscles are completely relaxed, with more or less divergence of visual lines. By the aid of stereographs upon which the stereographic interval exceeds the observer's interocular distance, binocular vision by optic divergence is readily attained after a reasonable degree of muscular control of the eyes has been attained by practice. But for obvious reasons the external rectus muscles are comparatively but little under the control of the will, and $7^{\circ}$ or $8^{\circ}$ of such divergence is probably about a maximum for normal eyes.

I have elsewhere shown (Am. Jour. Sci., May, 1882) that the ciliary muscle is also subject to the control of the will, though its action is most generally automatic. My observation accords with that of Mr. Judd that vision with a single eye is rarely if ever equal in distinctness to that with two eyes. But the accommodation of the single eye improves with time.

W. Le Conte Stevens.

Rensselater Polytechnic Institute, Troy, N. Y.

THE NORTHERN DURCHMUSTERUNG.

THE Durchmusterung charts of the northern 